\title{
IMPLEMENTASI METODE UP SELLING PADA SISTEM INFORMASI PENJUALAN
}

\author{
Novri Hadinata $^{1}$, Kurniawan $^{2}$, Inggri ramadanti utami ${ }^{3}$ \\ Universitas Bina Darma $1,2,3$ \\ Jalan Jenderal Ahmad Yani No.3 Palembang \\ Sur-el :novri_hadinata@binadarma.ac.id1, Kurniawan@binadarma.ac.id ${ }^{2}$ \\ Inggriramadanti06@gmail.com ${ }^{3}$
}

\begin{abstract}
General Sudirman eye center is a clinic that is engaged in optics and pharmacies offer various types of eyewear items needed by customers. but sometimes customers find it difficult to choose the type of glasses they want and cannot know the price of similar items because there is no online website in the Sudirman eye center so customers must come directly to the clinic sometimes there is no recommendation system for goods from company employees to prospective customers, this results in the loss of opportunities for profit because customers may choose to buy elsewhere. This leads to consumer discontent with the service and has an impact on the decline in sales turnover, by building an online website that implements an up selling method which is a system to offer goods that are one level above that provides opportunities for prospective customers to choose products related to the product provided by the seller. Prospective customers who have chosen the product category will be given a choice of some similar or more expensive products.
\end{abstract}

Keywords: sales, up selling, online websites

\begin{abstract}
Abstak: Jendral sudirman eye center adalah klinik yang bergerak di bidang optik danapotek menawarkan berbagai jenis barang kacamata yang dibutuhkan oleh pelanggan. namun terkadang pelanggan sulit untuk memilih barang jenis kacamata yang di inginkan dan belum bisa mengetahui harga barang sejenisnya karena belum adanya website online di jendral sudirman eye center sehingga pelanggan harus datang langsung ke klinik terkadang tidak adanya sistem rekomendasi barang dari karyawan perusahaan terhadap calon pelanggan, hal ini mengakibatkan hilangnya peluang untuk mendapatkan keuntungan karena bisa jadi pelanggan memilih membeli di tempat lain. Hal tersebut menyebabkan ketidakpuasaan konsumen terhadap layanan dan berdampak terhadap turunnya omset penjualan, dengan membangun website online yang menerapkan metode up selling yang merupakan sistem untuk menawarkan barang yang satu level diatasnya yangmenyediakan kesempatan untuk calon pelanggan memilih produk yang berkaitan dengan produk yang di sediakan olehpenjual. Calon pelanggan yang sudah memilih kategori produk akan diberikan pilihan beberapa produk sejenis yangsenilai ataupun yang lebih mahal.
\end{abstract}

Kata kunci : penjualan, up selling,website online

\section{PENDAHULUAN}

Jenderal sudirman eye center (JSEC) adalah suatu usaha yang bergerak dibidang klinik optik dan apotek, yang menjual berbagai jenis barang kacamata dan obat-obat kesehatan, terutama jenis perlengkapan kacamata seperti lensa dan frame. Dalam penjualan dan pemasaran pada saat ini belum memanfaatkan website sebagai media promosi dan pemesanan secara online. Sistem yang bejalan saat ini dalam melakukan penjualan di jendral sudirman eye center masih menggunakan media interaksi secara langsung antara pelanggan dan karyawan. Dari sisi lain terkadang tidak adanya sistem rekomendasi barang dari karyawan perusahaan 
terhadap calon pelanggan, hal ini mengakibatkan hilangnya peluang untuk mendapatkan keuntungan karena bisa jadi pelanggan memilih membeli di tempat lain. Hal tersebut menyebabkan ketidakpuasaan pelanggan Dikarenakan permasalahan tersebut, Jendral sudirman eye center (JSEC) membutuhkan Metode Up selling yang menawarkan kepada pelanggan untuk membeli produk yang lebih baik dibandingkan yang dia akan beli serta memiliki kualitas yang baik. (Willybrodus.,, Sukmaaji, \& Soebijono, 2015). Suatu sistem penjualan online yang dapat membantu proses dokumentasi data yang terintegrasi, Dengan adanya Sistem Penjualan ini, diharapkan dapat membantu jendral sudirman eye center, dalam Penjualan yang dilengkapi dengan cara pendekatan pelanggan filosofi $C R M$ didalam metode up selling agar mempermudah pelanggan memilih produk yang sama dengan kualitas yang baik dan membantu penjualan menawarkan barang kepadapelanggan. (Adhi Tama, 2019).

Sistem Informasi merupakan suatu kegiatan dari prosedur-prosedur yang diorganisasikan, bilamana dieksekusi akan meyediakan informasi untuk mendukung pengambilan keputusan dan pengedalian didalam organisasi. (Astuti, 2011). Sistem Informasi dapat diimplementasikan dalam berbagai bidang yang bertujuan untuk membantu memberikan kemudahan dalam mengolah data agar menjadi informasi yang dapat digunakan untuk menganalisis kondisi yang dialami. Salah satu bidang yang sudah banyak memanfaatkan Sistem Informasi adalah Bidang Penjualan Barang. Mulai dari promosi, pemesanan sampai dengan pembayaran, Sistem Informasi sanagat membantu dalam mempermudah proses bisnis dalam bidang penjualan tersebut. Salah satu metode yang digunakan dalam membangun Sistem Informasi untuk bidang Penjualan Barang adalah dengan metode up Selling. Up Selling merupakan strategi menjual dengan menawarkan produk yang sama tetapi memiliki nilai jual yang lebih tinggi dengan kompensasi tambahan manfaat bagi konsumen. up selling adalah upaya meningkatkan loyalitas pelanggan dan meningkatkan penjualan dengan mengarahkan pelanggan untuk membeli produk yang lebih mahal. Sehingga website toko online yang dibuat memberikan penjelasan atas spesifikasi produk yang dijual. (Purwaningtias, 2018)

\section{METODOLOGI PENELITIAN}

Identifikasi masalah dalam penelitian menggunakan metode analisis deskriptif, yaitu suatu metoda yang berusaha mengumpulkan, menyajikan serta menganalisa data sehingga dapat memberikan gambaran yang cukup jelas mengenai permasalahan yang sedang dikembangkan.

Sedangkan untuk membangun sistem informasi yang dierncanakan digunakan metode atau model Waterfall sebagai metode Pengembangan Sistem. Model waterfall menyediakan alur hidup perangkat lunak secara sekuensial dan terurut dimulasi dari analisis, desai, pengodean, pengujian dan tahap pendukung(Rosa A.S \& Shalahudin, 2015).

Tahapan-tahapan metodologi waterfall adalah sebagai berikut ; 
1. Analisis Kebutuhan Perangkat Lunak

Proses pengumpulan kebutuhan dilakukan secara intensif untuk mespefikasikan kebutuhan perangkat lunak agar dapat dipahami perangkat lunak seperti apa yang dibutuhkan oleh user. Spesifikasi kebutuhan perangkat lunak pada tahap ini perlu untuk didokumentasikan.

2. Desain Desain perangkat lunak

Proses ini merupakan proses multi langkah yang fokus pada desain pembuatan program perangkat lunak termasuk struktur data, arsitektur perangkat lunak, representasi antarmuka, dan prosedur pengodean. Tahap ini mentranlasi kebutuhan desain agar dapat diimplementasikan menjadi program pada tahap selanjutnya.

3. Pembuatan Kode Program

Desain harus ditranslasikan kedalam program perangkat lunak. Hasil dari tahap ini adalah program komputer sesuai dengan desain yang dibuat.

4. Pengujian

Pengujian pokus pada perangkat lunak secara dari segi logik dan fungsional dan memastikan bahwa semua bagian sudah diuji. Hal ini dilakukan untuk meminimalisir kesalahan (error).

\section{HASIL DAN PEMBAHASAN}

Output berupa informasi rekomendasi up selling, akan diberikan oleh Sistem Informasi yang akan dibangun. Untuk memperoleh Output yang diharapakan, maka harus dilakukan pencatatan produk, pengetahuan produk untuk membangun sistem penjualan online. Teknik rekomendasi up selling bisa meningkatkan omset perusahaan Adapun langkah-langkah sistem kebutuhan yang di usulkan sebagai berikut :

1. Pencatatan jenis-jenis kacamata, aksesoris kacamata yang berkualitas baik dan kegunaannya akan di jelaskan pada tabel dibawah ini.

Tabel 1pengetahuan kegunaan barang

\begin{tabular}{lll}
\hline No & Barang & Kegunaan \\
\hline 1. & $\begin{array}{l}\text { Kacamata anti } \\
\text { radiasi }\end{array}$ & $\begin{array}{l}\text { Berfungsi untuk } \\
\text { melindungi mata } \\
\text { dari sinar radiasi }\end{array}$ \\
2. & Silicone eyeglass & $\begin{array}{l}\text { Kegunaanya untuk } \\
\text { bantalan hidung } \\
\text { ketika memakai } \\
\text { kacamata }\end{array}$ \\
\hline
\end{tabular}

2. Pencataan produk yaitu pemberian pengetahuan tentang pemuas nilai produk. Berikut contoh salah satu pengetahuan pemuas nilai produk atau pengetahuan kegunaanya kepada pelanggan yang terdapat pada tabel dibawah ini sebagai berikut.

Tabel 2 pengetahuan nilai barang

\begin{tabular}{|c|c|}
\hline Barang & Nilai \\
\hline $\begin{array}{l}\text { Kacamata } \\
\text { anti radiasi }\end{array}$ & $\begin{array}{l}\text { Pelanggan tidak takut lagi jika } \\
\text { terkena sinar matahari langsung } \\
\text { ke kontak mata, dan pelanggan } \\
\text { merasa nyaman dengan adanya } \\
\text { silicone eyeglass }\end{array}$ \\
\hline $\begin{array}{l}\text { Silicone } \\
\text { eyeglass }\end{array}$ & \\
\hline
\end{tabular}

3. fitur up selling bertujuan untuk mengarahkan pelanggan untuk membeli produk yang lebih mahal atau menawarkan produk yang memiliki kualitas yang tinggi. Analisa up selling didapatkan dengan mendapatkan id 
produk, paket produk dan harga produk lalu melakukan query produk yang serupa. jika pelanggan memilih salah satu produk maka akan muncul paket produk dibawahnya yang memiliki nilai sedikit lebih tinggi namun memiliki kualitas yang lebih baik.

Output yang diharapkan dari fitur metode $u p$ selling (menggunakan salah satu contoh barang kacamata jendral sudirman eye center dari database dapat dilihat pada tabel 3 .

Tabel 3 output yang diharapkan dari fitur up

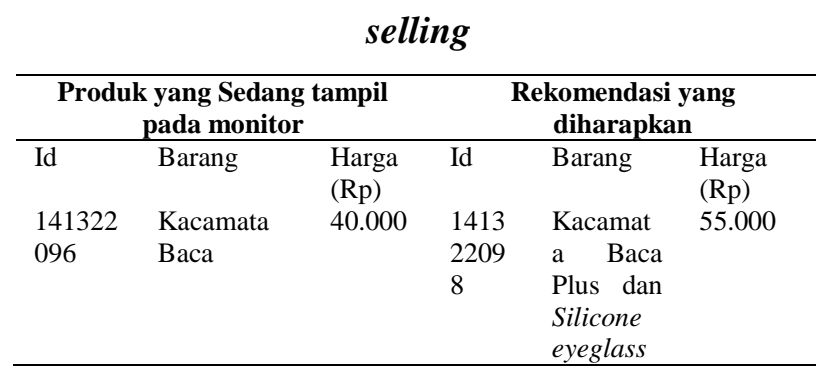

Agar tercapai output yang dinginkan, yang dilakukan dalam penerapan up selling, misalnya id barang = 141322096 Nama barang kacamata baca. Maka sistem akan melakukan select terhadap id barang (141322096), katagori paket barang (untuk mendapatkan produk yang serupa) dan harga jual yang lebih tinggi dengan kualitas dan tambahan lain jika itu termasuk didalam paket menu up selling barang maka akan muncul penawaran menu up selling dengan id barang =141322098 nama barang Kacamata baca plus dan mendapatkan item lain Silicone eyeglass.

Ketika pelanggan login dan memilihbarang/produk dan memasukkanya kedalam keranjang maka akan muncul sistempenawaran up selling, menawarkan produk paket yang kualitasnya yang baik,Untuk mendapatkan katagori yang serupa dengan produk yang bersangkutan dan harga jual produk yang lebih tinggi, dillakukan atau di buat flowchart dari alur fitur up selling seperti pada gambar 1.

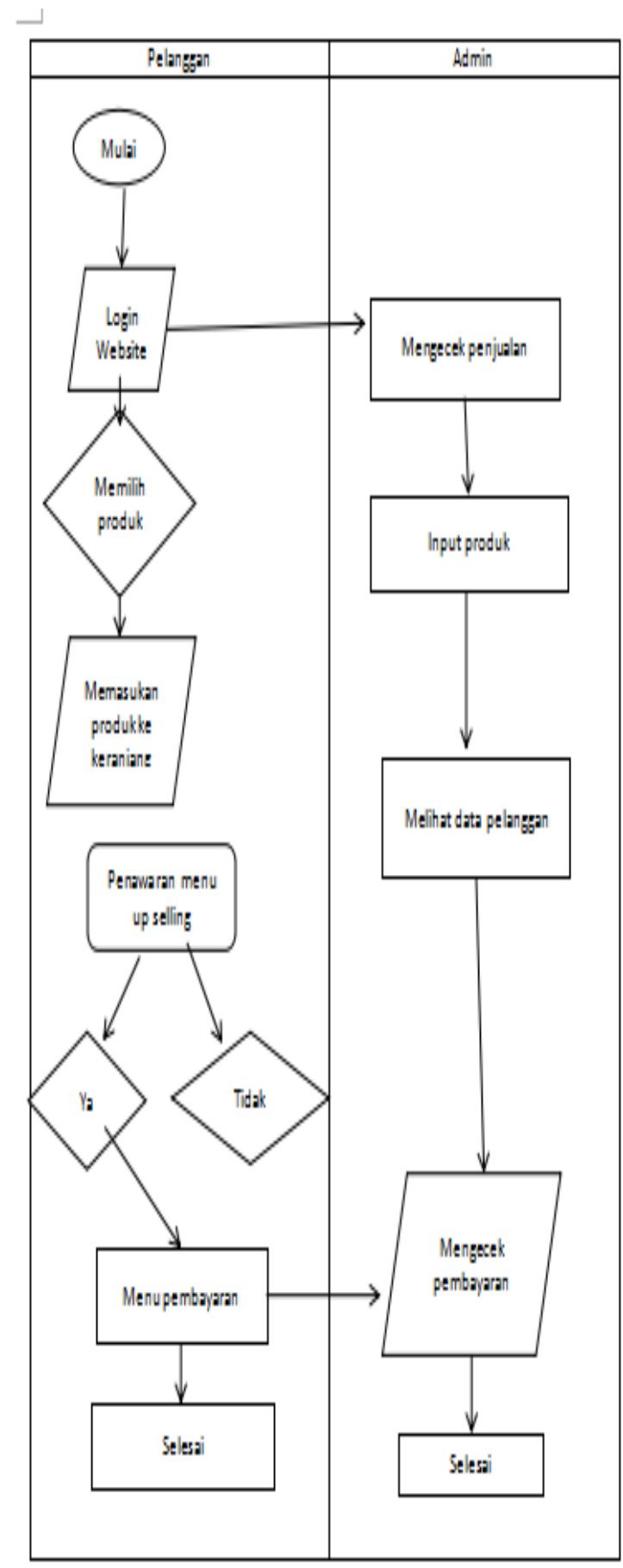

Gambar 1 flowchart Sistem yang di usulkan 
Setelah melalui tahap uji coba, sistem mampu menghasilkan sistem yang menampilkan login admin, registrasi pelanggan, informasi produk, rekomendasi up selling daftar member dan input barang oleh admin. Login admin dapat di lihat pada gambar 2.

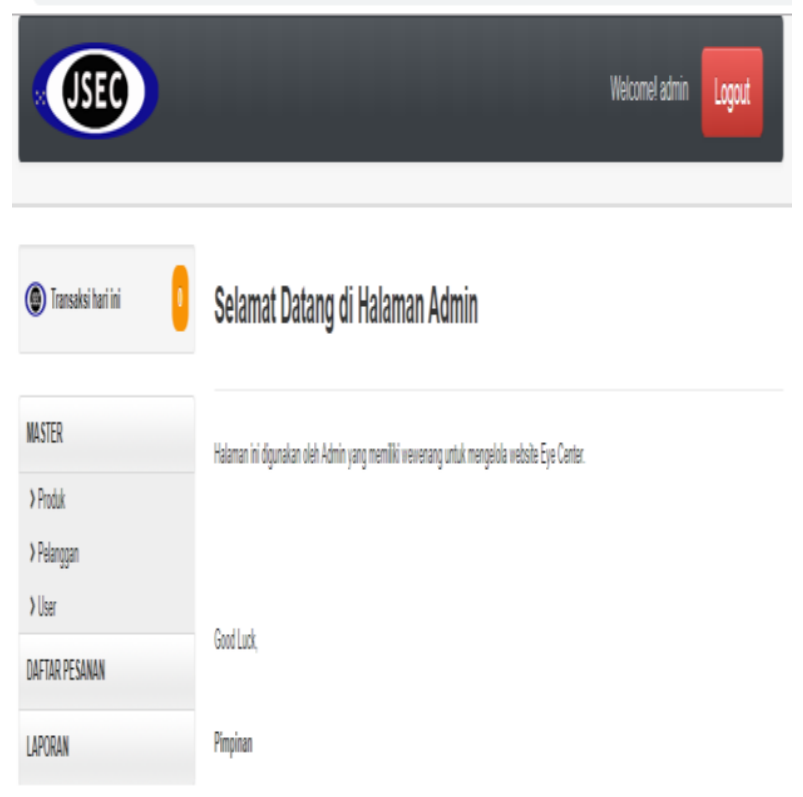

\section{Gambar 2 Login Admin}

Berdasarkan Gambar 2, Login Admin bisa menginputkan data pelanggan dan daftar pemesanan barang yang sudah dipesan pelanggan.

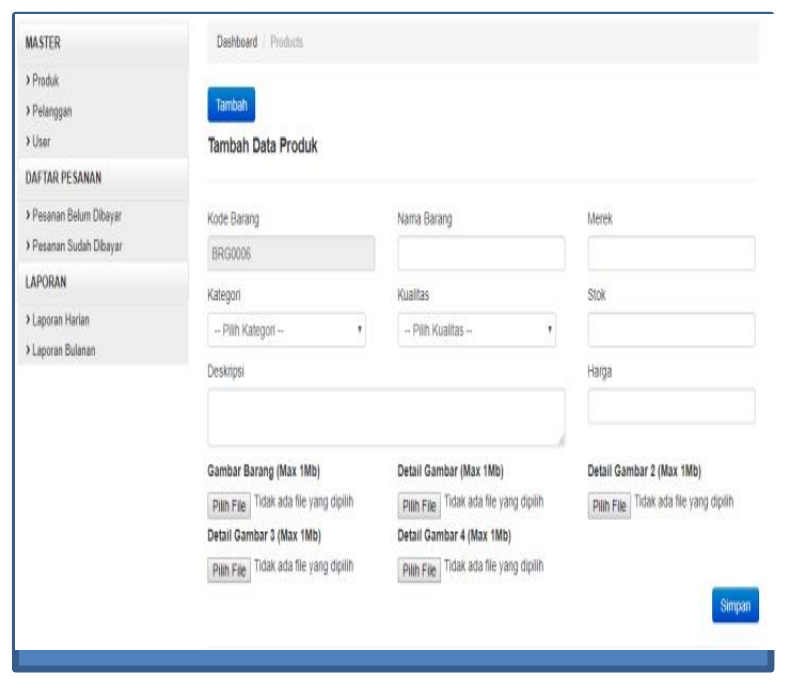

Gambar 3 input barang oleh admin
Berdasarkan Gambar 3, Admin menginputkan barang berdasarkan katagori barang tersebut dan mengupload foto barang, serta menginputkan deskripsi fungsi barang yang terdapat didalam foto.

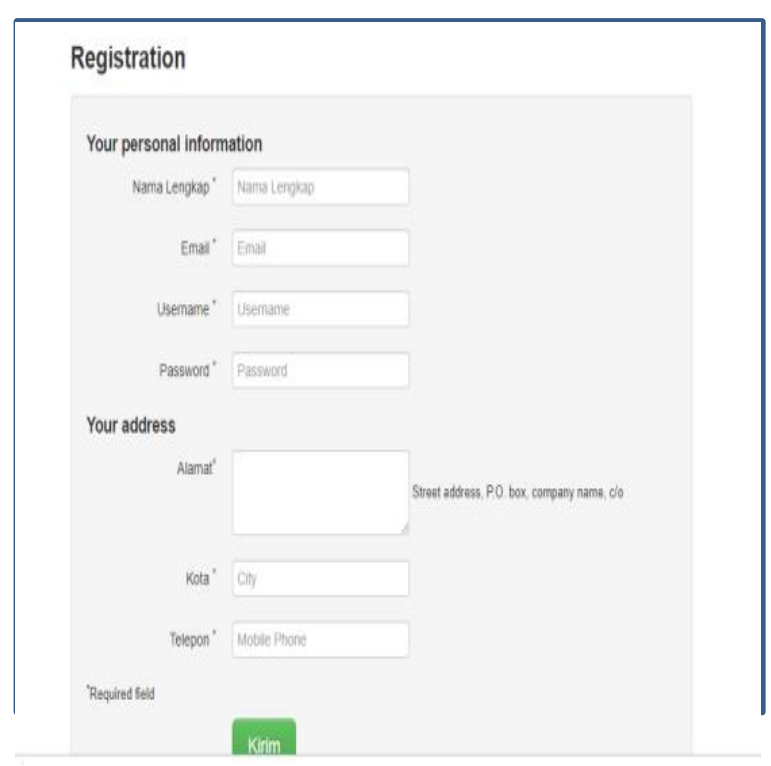

\section{Gambar 4 registrasi pelanggan}

Berdasarkan Gambar 4, pelanggan diharuskan registrasi agar bisa membeli barang di website online jendral sudirman eye center, dengan cara mengisi dan melengkapi form yang ada seperti nama lengkap, email dan lainya setelah itu kirim.
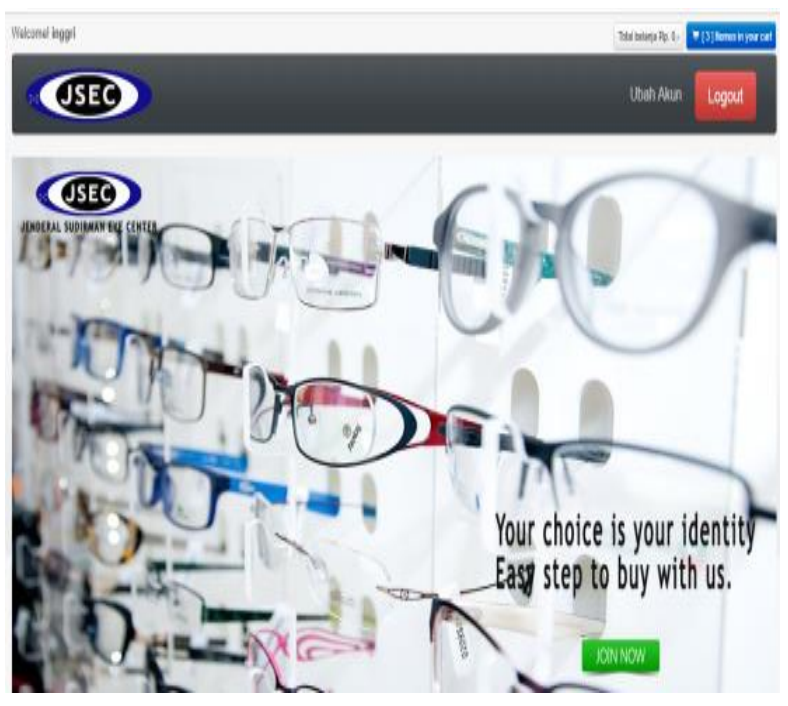

Gambar 5 login pelanggan 
Berdasarkan Gambar 5, ketika pelanggan sudah login maka akan tampil halaman home yang sudah ada keranjang belanja disisi kanan atas.

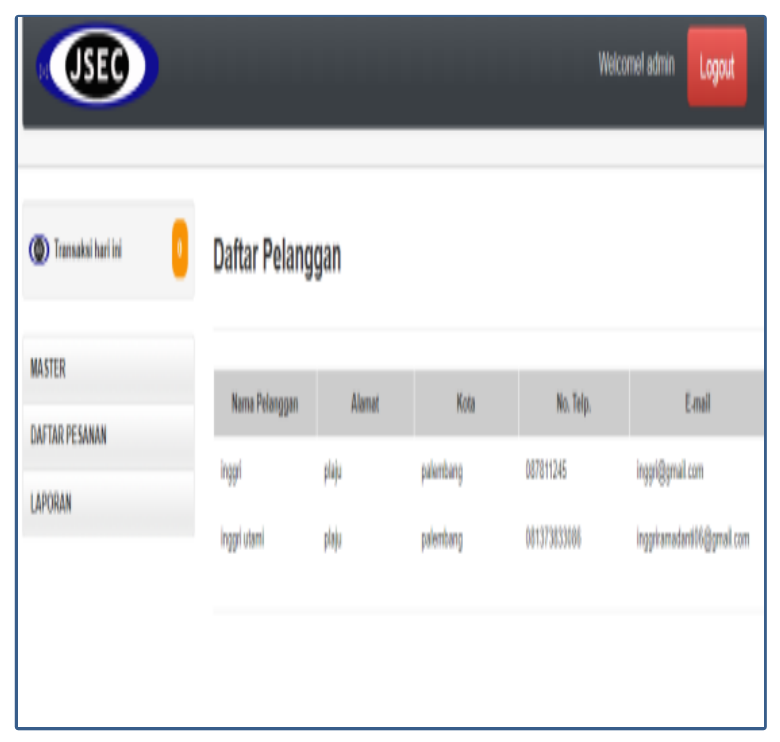

\section{Gambar 6 daftar pelanggan}

Berdasarkan Gambar 6 dapat dilihat sistem menampilkan daftar pelanggan yang sudah registrasi dan login di website online jendral sudirman eye center.

Selain itu, sistem yang dibangun juga dapat mempilkan informasi produk yang ingin di beli. Halaman tersebut dapat dilihat pada gambar 7.

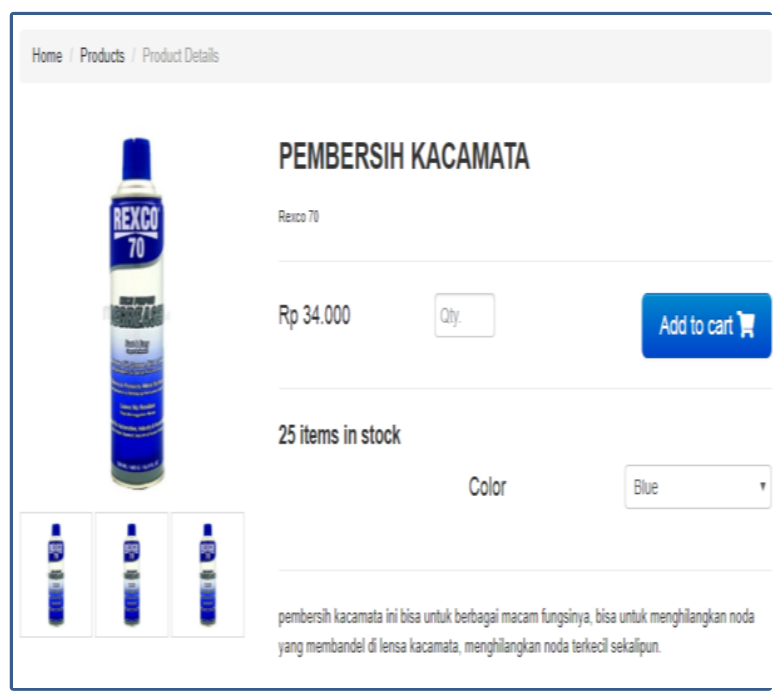

Gambar 7 informasi produk
Berdasarkan Gambar 7, dapat dilihat bahwa Sistem dapat menyediakan informasi produk yang ingin di beli oleh pelanggan berupa fungsi, warna produk dan harga produk.

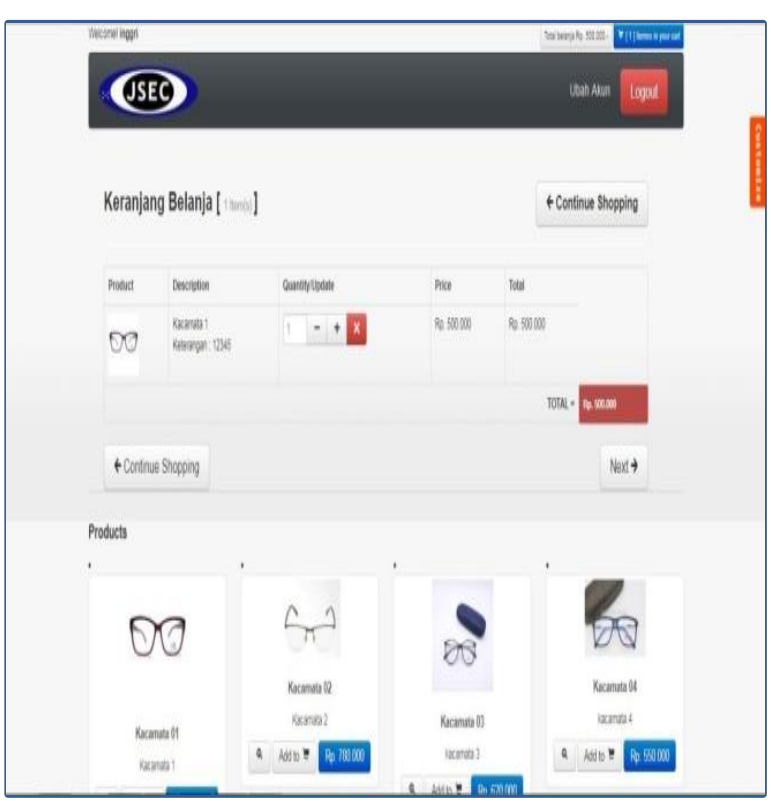

Gambar 8 rekomendasi up selling

Berdasarkan Gambar 8, dapat dilihat bahwa sistem Informasi yang dibuat dapat Memberikan rekomendasi produk up selling pada pelanggan sesuai katagori barang yang sama atau sejenis.

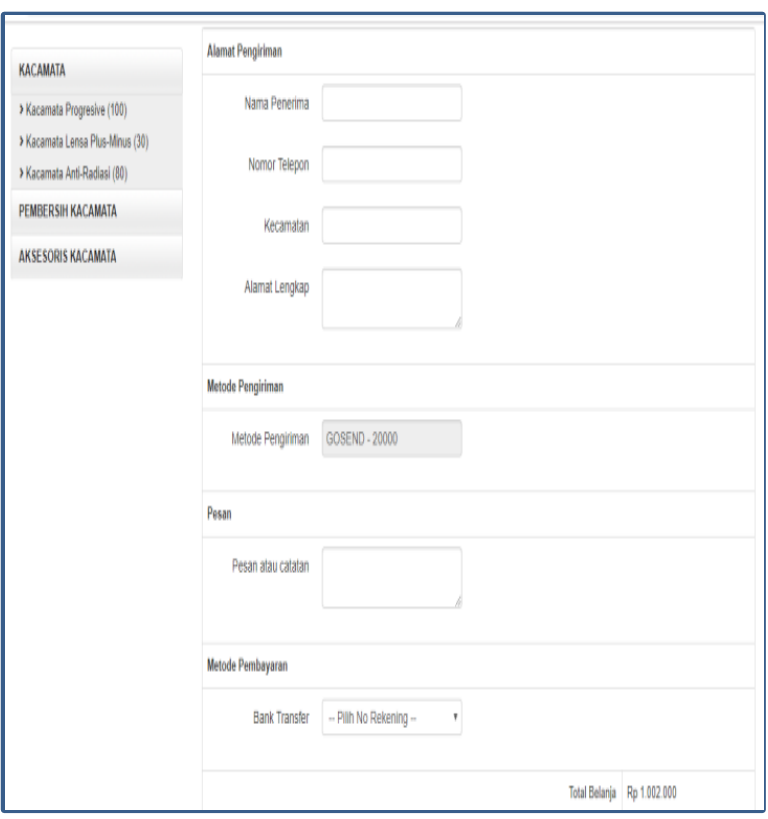


Gambar 9 menampilkan halaman pembayaran yang dapat dilakukan melalui via transfer, dan harus mengisi form alamat pengiriman, pesan yang bisa di isi catatan.

\section{SIMPULAN}

Setelah melakukan pembuatan pada website optik online dengan implementasi metode Up Selling studi kasus jendral sudirman eye center maka dapat ditarik kesimpulan bahwa website optik online yang telah dibuat dapat menampilkan informasi tentang pengetahuan barang yang berisi pengetahuan manfaat barang, serta pengetahuan tentang nilai kepuasan yang diberikan produk kepada konsumen dan website dapat memberikan rekomendasi pilihan produk paket terhadap produk serupa yang mempunyai nilai lebih tinggi atau memiliki harga lebih mahal dari produk yang bersangkutan atau rekomendasi up selling. Melalui website ini, pelanggan dapat melakukan kegiatan yang meliputi pencarian dengan lebih mudah, pencarian dapat dilakukan dengan memberikan masukkan yang berupa nama produk atau merek produk atau paket produk atau manfaat produk.

Selain itu melalui website ini pelanggan juga dapat melakukan pembelian dan pembayaran secara online dan real time tanpa harus datang ke toko. Berdasarkan hasil uji coba didapatkan bahwa sistem ini mampu mengatasi sistem yang digunakan sebelumnya itu masih menggunakan dokumentasi sehingga pencaatan sering terjadi selilsih dan menghasilkan dan mencetak laporan penjualan, stok produk dan transaksi penjualan.

\section{DAFTAR PUSTAKA}

Astuti, Puspita Dwi., Sistem Informasi Penjualan Obat Pada Apotek Jati Farma Arjosari. Speed-sentra penelitian engineering dan edukasi, 3(4). 2017.

Adhi Tama, Bayu (2009). Implementasi Teknik Data Mining di Dalam Konsep Customer Relationship Management. 14 November 2009.

Purwaningtias, Fitri,. Penerapan product knowledge dan strategi upselling pada chandra tech palembang. Jurnal Informatika: Jurnal Pengembangan IT, 3(2):253-258, 2018.

Rosa A.S. \& Shalahudin. Rekayasa Perangkat Lunak Terstruktur dan Berorientasi Objek. Bandung: Informatika. 2015.

Willybrodus, Malkus., Sukmaaji, Anjik., and Soebijono, Tony., Re-Desain Website CV Planktoon Dengan Metode Up Selling Dikombinasikan Dengan Sosial Media Untuk Peningkatan Penjualan. JAVA Journal of Electrical and Electronics Engineering, 13(2), 2015. 